\title{
An economic model of the evolution of the gender performance ratio in individual sports
}

Citation for published version (APA):

Dupuy, A. (2010). An economic model of the evolution of the gender performance ratio in individual sports. ROA. ROA Research Memoranda No. 6 https://doi.org/10.26481/umaror.2010006

Document status and date:

Published: 01/01/2010

DOI:

10.26481/umaror.2010006

Document Version:

Publisher's PDF, also known as Version of record

\section{Please check the document version of this publication:}

- A submitted manuscript is the version of the article upon submission and before peer-review. There can be important differences between the submitted version and the official published version of record. People interested in the research are advised to contact the author for the final version of the publication, or visit the DOI to the publisher's website.

- The final author version and the galley proof are versions of the publication after peer review.

- The final published version features the final layout of the paper including the volume, issue and page numbers.

Link to publication

\footnotetext{
General rights rights.

- You may freely distribute the URL identifying the publication in the public portal. please follow below link for the End User Agreement:

www.umlib.nl/taverne-license

Take down policy

If you believe that this document breaches copyright please contact us at:

repository@maastrichtuniversity.nl

providing details and we will investigate your claim.
}

Copyright and moral rights for the publications made accessible in the public portal are retained by the authors and/or other copyright owners and it is a condition of accessing publications that users recognise and abide by the legal requirements associated with these

- Users may download and print one copy of any publication from the public portal for the purpose of private study or research.

- You may not further distribute the material or use it for any profit-making activity or commercial gain

If the publication is distributed under the terms of Article $25 \mathrm{fa}$ of the Dutch Copyright Act, indicated by the "Taverne" license above, 
Maastricht University

Research Centre for Education and the Labour Market | ROA

\section{An economic model of the evolution of the gender performance ratio in individual sports}

Arnaud Dupuy

\section{ROA Research Memorandum}

ROA-RM-2010/6

Research Centre for Education and the Labour Market Maastricht University

P.O. Box 616, 6200 MD Maastricht, The Netherlands

$\mathrm{T}+31433883647 \mathrm{~F}+31433884914$

secretary-roa-sbe@maastrichtuniversity.nl www.roa.nl 


\title{
An economic model of the evolution of the gender performance ratio in individual sports
}

\author{
Arnaud Dupuy \\ ROA-RM-2010/6* \\ April 2010
}

Research Centre for Education and the Labour Market

Maastricht University

P.O. Box 616, 6200 MD Maastricht, The Netherlands

$\mathrm{T}+31433883647 \mathrm{~F}+31433884914$

secretary-roa-sbe@maastrichtuniversity.nl

www.roa.nl

\footnotetext{
* The ROA Research Memorandum Series was created in order to make research results available for discussion, before those results are submitted for publication in journals.
} 


\section{Abstract \\ An economic model of the evolution of the gender performance ratio in individual sports $^{* *}$}

This paper shows that gender world record ratio in four disciplines, i.e. marathon, triple jump, pole vault and $\mathbf{8 0 0}$ meters, follows a S-shape over time. It is argued that this pattern is initiated by a sudden drop in the social barrier for women to participate in these disciplines. This drop in social barrier materializes -later- by the authorization for women to participate at major events, such as the Olympic Games, in these disciplines. The paper builds a simple economic model of sector self-selection and human capital accumulation with intrinsic disutility (social barriers) to participate in some sectors. As social barriers are removed in a sector, the Gender Performance Ratio is show to follow a S-shape over time under very basic assumptions and calibrations. Ability selfselection, measured as the difference between mean ability of women in that sector and population mean, becomes more positive after removal of the social barrier.

JEL classification: J16, J7, N32

Keywords: Gender Performance Ratio; Sector self-selection; Human Capital investments

Arnaud Dupuy

ROA

Maastricht University

P.O. Box 616

6200 MD Maastricht

The Netherlands

a.dupuy@maastrichtuniversity.nl

** Second draft. The comments of Lex Borghans, Nabanita Datta Gupta, Didier Fouarge, Bart Golsteyn, Ben Kriechel, Sol Polachek and Michael Sattinger and participants at the 2009 EALE are acknowledged. 


\section{Introduction}

In the vast majority of individual sports, the performance of women relative to men has increased over time. For instance, as shown in Figure 1, the Gender World Record Ratio (GWRR hereafter) in many individual sports including speed skating, athletics (running and jumping disciplines) and swimming has increased since the early 1900s. The main reason for this pattern is the increased participation of women in sports activities and in particular in major sports events such as the Olympic games (OG) as depicted in Figure 2 (IOC, 2009). However, the evolution of the GWRR has not been uniform across disciplines. Zooming in on Figure 1, two groups of disciplines can be distinguished. The first group contains disciplines for which the evolution has roughly followed a constant trend over time, the left panel of Figure 3, whereas the second contains (athletics) disciplines, i.e. triple jump, pole vault, marathon and to a lesser extent 800 meters, for which the evolution of the GWRR follows a S-shape over time, the right panel of Figure 3 . $^{1}$

The question arises why the GWRR in the second group has followed a

\footnotetext{
${ }^{1}$ Note that this S-shape is not an artifact of world records in these disciplines but is also observed for other measures of performance as well. For instance, focussing on Marathon, Figure 4 indicates that the evolution of the GWRR is very similar to that of the gender year best performance ratio or even the ratio of gender winning time at the Boston marathon.
} 
S-shape. Formalizing the problem a bit, write $p_{i t}=b_{t} h_{i t}$ the performance at time $t$ of an athlete $i$ with ability $h_{i t}$ using technology $b_{t}>0$. Denote, $\bar{h}_{t}=\max _{i}\left\{h_{i t}\right\}$ the ability of the best athlete at $t$. The world record at time $t$ is by definition $w r_{t}=\max _{\tau<t}\left\{b_{\tau} \bar{h}_{\tau}\right\}$. The world record is broken at time $T$ if and only if $b_{T} \bar{h}_{T}>\max _{\tau<T}\left\{b_{\tau} \bar{h}_{\tau}\right\}$. This highlights two candidates to explain the S-shape evolution of the GWRR in the right panel of Figure 3: gender biased technical change (gender specific changes in $b_{t}$ ) or increased ability of women (gender specific changes in $\bar{h}_{t}$ ). The first explanation implies that the new techniques or technologies that have been introduced in these four disciplines have favored women relative to men while the second implies that the ability of women started increasing sharply relative to men. ${ }^{2}$

Although gender biased technical change could have led to such a differential behavior of the GWRR across events over time, this explanation has limited scope in practice for at least three reasons. First, long jump and

\footnotetext{
${ }^{2}$ In a related paper, Munasinghe et al. (2001) find that the evolution of world record breaking in Track and Field is similar to the evolution of US record breaking arguably local records set with fixed population. Munasinghe et al. argue that this evidence stems for the prominent role played by technological progress in the evolution of world record breaking as opposed to globalization. However, one can easily argue that 1) a significant share of world records in Track and Field are also US records and more important that 2) athletes breaking the US records are usually athletes competing at international competition (world championships, Olympics etc.) and therefore subject to increased competition among athletes following from the globalization and leading to increased human capital investments (increased training load, better nutrition, more massages, etc.), factors acknowledged in Munasinghe et al. as being part of the technological progress.
} 
triple jump are very similar events as far as technique and technology are concerned and yet only triple jump has witnessed a S-shape evolution of the GWRR. Second, although major changes in technology have occurred in the second group (S-shape group), the timing of these technological changes do not coincide with the timing of the S-shape in GWRR. For instance, the most important technological development in pole vault was the introduction of glass fiber poles in 1961. This occurred about 25 years before the GWRR started increasing sharply. Third, major changes in techniques occurred in events belonging to the first group too, i.e. without a S-shape evolution of the GWRR. For instance, the introduction of the Fosbury flop in 1968 is considered to be the major change in technique at high jump and this change has not affected significantly the GWRR at high jump.

The main source of differences in the evolution of the GWRR between disciplines in the left panel and (athletic) disciplines in the right panel must therefore be linked to a sharp increase in the ability of women athletes in these four disciplines. This could have materialized through i) self-selection: better women athletes started participating in these disciplines, and/or ii) greater human capital investments of women in these disciplines: women athletes in these disciplines started to train more/harder. The question remains why 
women's self-selection and human capital investments behavior have changed so much in these disciplines and not in others.

The answer to this question is linked to historical events related to women's participation at major events and in particular the OG or the World Championships (WC). ${ }^{3}$ Although women's participation at the OG started in 1900 with Tennis and Golf and was followed by swimming events in $1912,{ }^{4}$ it is not until 1928 that women were allowed to participate at athletics events. Even then, women's participation was limited to some disciplines such as short distance running, high jump and long jump. ${ }^{5}$ Similarly, although the participation of women at the athletics European Championships (EC) started in 1938 in Vienna and were combined with men's championships in 1946 in Oslo, only short run distances, long jump and high jump were programmed. Women's participation at the 800 meters would only occur in 1954 and 1960 for the EC and OG respectively. Women's marathon was introduced in 1982 for the EC and 1984 for the OG. Beyond the OG and EC events, women

\footnotetext{
${ }^{3}$ Note that the OG served as world championships until 1983 when the first independent world championships were organized in Helsinki.

${ }^{4}$ In 1912, only one individual swimming event was organized for women, the 100 meters freestyle. In 1920, women could also swim the 300 meters free style and as of 1924 women could compete on the same distances and styles as men, except for the 1500 meters. In 1968 , the 800 meters was created for women.

${ }^{5}$ The 800 meters was on the program of the 1928 Olympics but 3 women collapsed during the race which led to a general opinion that women could not safely run long distances, (Leigh and Bonin, 1974).
} 
had to wait until 1971 to be allowed to run the New York City marathon and one year later the Boston marathon. Similarly, women's triple jump and pole vault were only ratified by the International Association of Athletics Federations (IAAF) in 1990 and 1992 respectively. Triple jump appeared at the EC and OG for the first time in 1994 and 1996 respectively; pole vault in 1998 and 2000 respectively. ${ }^{6}$

In this paper, I build a (simple) economic model to explain the S-shape evolution of the GWRR in the second group of disciplines from a sudden drop in the disutility to participate in these disciplines. The three key ingredients of this model are i) sector (or discipline) self-selection as in Roy's model (Roy, 1951), ii) disutility (expected gains or intrinsic) differential across sectors and iii) sector specific human capital investments. Intuitively, if abilities across sectors are positively correlated, the model explains the S-shape evolution of the GWRR in the second group of disciplines as follows. The social barrier for women to practice these disciplines, that is partially materialized in their non authorization to participate at major events generates disutility, either

\footnotetext{
${ }^{6}$ Also, one might wonder why we do not observe a S-shape evolution of the GWRR at speed skating events while speed skating events for women were only organized for the first time at the 1960 winter OG. The answer is simply that although women's participation at the winter OG came on late, the International Skating Union had been organizing the World All-round Speed Skating Championships for Women since 1936 and unofficial Championships were already held in the years 1933-1935.
} 
in terms of expected income (prizes but also sponsorship) or intrinsic, for women to specialize in these disciplines. As a result, more talented female athletes will select other disciplines and/or women's investments in human capital specific to these disciplines will be lower than that of men. However, as soon as the social barrier drops, the disutility to specialize in these disciplines vanishes. This induces a change in the distribution of women over disciplines. Moreover, new generations of women will invest more in developing human capital specific to these disciplines which will lead each new generation of women selecting into these disciplines to have more human capital than previous generations and hence higher performance. The GWRR will consequently increase up until generations born after the drop of the social barrier in these disciplines have become athletes. The GWRR will then flatten as it reaches its new steady state. It is crucial to bare in mind that the authorization of women to participate at major events does not necessarily correspond to the timing of the drop in social barrier in the model. In fact, it is most likely that the drop in social barrier occurs a decade or more before women become authorized to participate at major events. For instance, women authorization to participate at the NYC marathon proceeded by 13 years the authorization for women to participate at the OG marathon. Sim- 
ilarly, the authorization for women to participate at the OG triple jump and pole vault events followed by about a decade the ratification by the IAAF of these disciplines for women.

It can be shown through simple calibration of the model that the model predicts a S-shape evolution of GWRR over time with 18-year window of increase in a sector for which social barriers vanish. The model also predicts that selection, as measured by the difference in performance between women selecting a sector and women in the population, into the sector for which social barriers drop is becoming more positive over time and follows a Sshape too.

The model also makes an important prediction about the timing of the drop in social barrier in a sector. The model predicts indeed that the end of the window of increase will occur when the generation born just after the drop of the social barrier reaches the age at which performance in that sector peaks. The year of the drop in social barrier is therefore given by subtracting the age of peak performance in that sector to the year corresponding to the end of the window of increase.

The remaining structure of the paper is as follows. The next section presents the model and illustrates the main feature of the model with a simple 
calibration. Section 3 concludes and discusses the relationship between the model developed in this paper and the literature on the evolution of the GPR.

\section{Model}

\section{$2.1 \quad$ Set up}

Consider an economy where individuals live for $A$ years. As in the standard human capital model, individuals invest full time in human capital early in life, say until $\bar{a}$ with $0<\bar{a}<A$, and then engage full time in consumption generating activities until they die at $A$.

For simplicity assume there are two sectors of activities only. Without loss of generality, think of sector 1 as a sector with potential social barriers, defined below as intrinsic disutility specific to sector 1, and sector 2 as a sector without such social barriers. For instance, sector 1 could be any of the disciplines in the right panel of Figure 3, say triple jump, and sector 2 any disciplines in the left panel, say long jump. Another noteworthy example is one where sector 1 is paid work and sector 2 home production, in which case the model can be used to describe the evolution of the Gender Pay Ratio (GPR) over time. 
Let individuals be born with endowed stock of human capital of two types, i.e. $h_{10}$ and $h_{20}$, and let $\varphi\left(h_{10}, h_{20}\right)$ and $\Phi\left(h_{10}, h_{20}\right)$ be the PDF and CDF respectively. Assume further that $C O V\left(h_{10}, h_{20}\right) \geq 0$. Let the initial distribution be constant over time and hence across age cohorts. Denote $h_{j a}, j=1,2$, human capital of type $j$ at age $a$. Let $s_{j a}$ be the time spent accumulating human capital of type $j$ at age $a$ with $s_{1 a}+s_{2 a}=1$ for all $a<\bar{a}$ and $s_{j a}=0$ for $a \geq \bar{a}$.

The accumulation of human capital of type $j$ through study is given by $g_{j}\left(h_{j a-1}\right) s_{j a}$. The evolution of the stock of human capital is not only driven by human capital investments but also by appreciation -early in life- and depreciation -late in life- over the life-cycle given by $\alpha_{j}+\frac{\beta_{j}}{2} a$. The change in the stock of human capital of type $j$ is thus given by:

$$
\dot{h}_{j a}=g_{j}\left(h_{j a-1}\right) s_{j a-1}+\alpha_{j}+\frac{\beta_{j}}{2} a
$$

Let $t_{j a}$ be the time spent working in sector $j$ at age $a$ with $t_{1 a}+t_{2 a}=1$ if $a \geq \bar{a}$ and $t_{1 a}=t_{2 a}=0$ else. Let an individual's utility ${ }^{7}$ at age $a$ be $U_{a}=\left(f_{1}\left(h_{1 a}, a\right)-B_{1}\left(h_{1 a}\right)\right) t_{1 a}+f_{2}\left(h_{2 a}, a\right) t_{2 a}$ where $f_{j}(x, a)$ is the (per unit

\footnotetext{
${ }^{7}$ Any convex function of $\left(f_{1}\left(h_{1 a}, a\right)-B_{1}\left(h_{1 a}\right)\right) t_{1 a}$ and $\left(f_{2}\left(h_{2 a}, a\right)-B_{2}\left(h_{2 a}\right)\right) t_{2 a}$ will yield a corner solution $t_{j a}=1$ and $t_{k a}=0, j \neq k$.
} 
of time) productivity/consumption of workers with $x$ units of human capital of type $j$ at age $a$ and, $B_{1}(x)$ indicates (per unit of time) social barrier leading to disutility of working in sector 1 for an individual with $x$ units of human capital of type 1.

At age $a \geq \bar{a}$, utility maximizing individuals specialize and engage full time in either sector 1 or 2 depending on $U_{1 a} \gtreqless U_{2 a}$. The problem for an individual born with human capital $h_{10}$ and $h_{20}$ is therefore to choose $s_{j a}$ and $t_{j a}, j=1,2$ for all $a \leq A$ to maximize life-cycle utility. Formally the problem reads as:

$$
\max _{s_{j a}, t_{j a}} \int_{\bar{a}}^{A} e^{-\rho t} U_{a} d a
$$

so that :

$$
\begin{aligned}
U_{a}= & \left(f_{1}\left(h_{1 a}, a\right)-B_{1}\left(h_{1 a}\right)\right) t_{1 a}+f_{2}\left(h_{2 a}, a\right) t_{2 a} \\
& t_{1 a}=t_{2 a}=0 \text { if } a<\bar{a} \\
& t_{1 a}+t_{2 a}=1 \text { if } a \geq \bar{a} \\
& s_{1 a}+s_{2 a}=1 \text { if } a<\bar{a} \\
& s_{1 a}=s_{2 a}=0 \text { if } a \geq \bar{a} \\
\dot{h}_{j a}= & g_{j}\left(h_{j a-1}\right) s_{j a}+\alpha_{j}+\frac{\beta_{j}}{2} a
\end{aligned}
$$

where $\rho$ is the discount rate. 
The solution to this problem can be obtained using optimal control techniques although, even for this simple model, general closed form solutions are unlikely to exist. However, the essence of the model and its application to the GWRR is best understood with further simplifications and in particular with assumptions 1 and 2 below.

Condition 1 Monotonicity in human capital accumulation across sectors after $\bar{a}: \alpha_{1}=\alpha_{2}=\alpha$ and $\beta_{1}=\beta_{2}=\beta$, so that $h_{1 a}>h_{2 a}$ for all $a>\bar{a}$ if $h_{1 \bar{a}}>h_{2 \bar{a}}$

Condition 2 Monotonicity in utility across sectors. $f_{j}(.,$.$) and B_{1}($.$) are$ functions so that $f_{1}\left(h_{1 a}, a\right)-B_{1}\left(h_{1 a}\right)>f_{2}\left(h_{2 a}, a\right)$ for all $\bar{a}<a \leq A$ if $h_{1 a}>h_{2 a}$.

Assumptions 1 and 2 guarantee that individuals' optimal career path is to work each year in the same sector provided the economy remains unchanged over the life cycle. Indeed, we have $f_{1}\left(h_{1 a}, a\right)-B_{1}\left(h_{1 a}\right)>f_{2}\left(h_{2 a}, a\right)$ for all $A \geq a>\bar{a}$ if $h_{1 \bar{a}}>h_{2 \bar{a}}$. Define $\bar{h}_{j a}\left(\underline{h}_{j a}\right)$ as the stock of human capital at age $a$ if one invests full time in ability of type $j$ (respectively $k$ ), that is, if $s_{j a}=1$ (respectively 0) for all $a \leq \bar{a}$. Assumptions 1 and 2 imply that individuals will invest full time in accumulating human capital of type 1 and work full 
time in sector 1 if $f_{1}\left(\bar{h}_{1 \bar{a}}, \bar{a}\right)-B_{1}\left(\bar{h}_{1 \bar{a}}\right)>f_{2}\left(\bar{h}_{2 \bar{a}}, a\right)$. Note that this choice depends on: $\left(h_{10}, h_{20}\right), g_{j}(),. f_{j}(.,$.$) and B_{1}($.$) .$

\subsection{Calibration}

As an illustration, I calibrate the model assuming that initial stock of human capital follows a bivariate normal distribution with mean $(2,0.95 \times 2)$ and variance covariance matrix $\Sigma=\left(\begin{array}{cc}1 & 0.95 \\ 0.95 & 0.95^{2}+0.9^{2}\end{array}\right) .{ }^{8}$ The production function is assumed to be similar in both sectors and linear in human capital with unitary slope. The stock of human capital is assumed to increase by 0.05 units per unit of time invested and does not vary with age (no appreciation nor depreciation over the life cycle, $\alpha=\beta=0$ ). The initial social barrier increases linearly in the stock of human capital of type 1 with slope equal to

\footnotetext{
${ }^{8}$ Note that the S-shape can be generated with low (though positive) correlation between abilities. It generally depends on the initial position of the selection line with respect to the distribution of inate abilities, i.e. depends on $\Phi(.,),. g_{j}(),. f_{j}($.$) and B_{1}($.$) . Such$ examples are available from the author upon request.
} 
$1 / 3$. This is summarized as follows:

$$
\begin{aligned}
h_{20} & \sim N(2,1) \text { and } e \sim N(0,1) \\
h_{10} & =0.95 h_{20}+0.9 e \\
g_{j}\left(h_{j a}\right) & =0.05 \text { for } j=1,2 \\
f_{j}\left(h_{j a}, a\right) & =h_{j a} \\
B_{1}\left(h_{1 a}\right) & =\frac{B-1}{B} \times h_{1 a} \text { with } B=1.5 \\
\bar{a} & =19
\end{aligned}
$$

Note that this calibration satisfies assumptions 1 and 2, guaranteeing no switching sectors over the life-cycle (at given $g_{j}, f_{j}$ and $B_{j}$ ). This means that individuals will select sector 1 over sector 2 and remain in that sector over the life cycle, provided the economy does not change, if $\bar{h}_{1 \bar{a}}>B \times \bar{h}_{2 \bar{a}}$, that is if their maximum stock of human capital of type 1 at age $\bar{a}=19$ exceeds $B$ times their maximum stock of human capital of type 2. Figure 5 depicts this self-selection given the calibration of the model above. The figure plots the distribution of $\left(\bar{h}_{1 \bar{a}}, \bar{h}_{2 \bar{a}}\right)$ together with the selection line $\bar{h}_{1 \bar{a}}=B \times \bar{h}_{2 \bar{a}}$. Those individuals lying above (below) the line select sector 1 (respectively 2 ). The figure also shows how a drop in social barriers $B$ from 1.5 to 1 will 
lead to a twist clockwise in the selection line, inducing some individuals with relatively high type 1 human capital to switch from sector 2 to sector 1 .

Within age cohorts, the highest productivity in sector 1 is determined by the productivity of the worker supplying the highest stock of type 1 human capital. Collecting the highest productivity in sector 1 for each age cohort yields the highest productivity age profile in sector 1 as plotted in Figure 6 . Given our assumptions about human capital depreciation and production, this profile is concave and reaches a maximum at 33 years old. In this calibration, this means that the world record in sector 1 is set at about 7.28 prior to the drop in social barriers by a worker aged 33 .

Suppose that prior to $T=0$, the economy is so that $B=1.5$. At time $T=0, B$ drops unexpectedly from 1.5 to 1 . Figure 7 shows the actual distribution of human capital the cohort of individuals aged 19 at $T=0$ so that these individuals have made their human capital decisions prior to the drop in the social barrier. Within this cohort, those with $\bar{h}_{1 \bar{a}}>B \times \bar{h}_{2 \bar{a}}$ have invested full time type 1 human capital and therefore moved up compared to their initial position in the distribution of human capital $\varphi\left(h_{10}, h_{20}\right)$ whereas those with $\bar{h}_{1 \bar{a}} \leq B \times \bar{h}_{2 \bar{a}}$ have invested full time in type 2 human capital and therefore moved to the right compared to their initial position in the 
distribution of human capital $\varphi\left(h_{10}, h_{20}\right)$.

Without the drop in social barrier $B$, individuals that invested in type $j$ human capital would have selected sector $j$. However, since $B$ drops, utility in sector 1 increases relative to sector 2 and this especially for individuals with high type 1 human capital. Going back to the cohort aged 19 at $T=0$, Figure 8 shows that the drop in $B$ will induce some individuals to switch from sector 2 to sector 1 . Call these individuals "switchers $0 "$ ". Although "switchers $0 "$ have not invested in type 1 human capital, they have a relatively high initial stock. Note that Figure 8 could be generated for all cohorts of individuals 19 or older at $T=0$, and a similar pattern would be observed. This means that for all cohorts of individuals aged 19 or more at $T=0$, we can collect the highest productivity in sector 1 for "switchers 0 " and plot the highest productivity age profile of "switchers 0" as in Figure 9. Whether this profile is above or below the profile of those that would also have selected sector 1 without the drop in social barriers, that is whether a new world record will be set at $T=0$, depends on the calibration of the model.

However, this is not the most interesting feature of the model. The important mechanism put forward in this model however is that in contrast to cohorts older than 19 at $T=0$, cohorts younger than 19 at $T=0$ have (lim- 
ited) time to adjust their human capital investments before entering either sectors of activity. For instance, the cohort aged 18 at $T=0$, has still one year to invest in human capital. Among those that invested full time in type 2 human capital until $T=0$, those with relatively high innate stock of type 1 human capital might find it profitable to invest their last year full time in developing type 1 human capital. Call these individuals "switchers 1". At $T=1$, three groups of workers can be distinguished in sector 1 : i) workers aged between 19 and $A$ that invested full time in type 1 human capital, ii) "switchers 0 " now aged between 20 and $A$ and iii) "switchers 1 " aged 19 that invested 18 years in type 2 human capital and only their last year in type 1 human capital. Figure 10 indicates for each group the highest productivity age profile. As calibrated the world record at $T=1$ is unchanged.

At $T=2$, four groups of workers can be distinguished in sector 1: i) workers aged between 19 and $A$ that invested full time in type 1 human capital, ii) "switchers 0 " now aged between 21 and $A$, iii) "switchers 1 " now aged 20 and "switchers 2" aged 19 that invested 17 years in type 2 human capital and only their last 2 years in type 1 human capital. Figure 11 indicates for each of these groups the highest productivity age profile. As calibrated the world record at $T=2$ is unchanged. 
We can go on until the world record will finally be broken. In our calibration this will happen at $T=15,15$ years after the drop in $B$. As depicted in Figure 12, the WR will be broken by the best "switcher 4" at the age of 30 years old.

It should be clear that each new generation will have workers with potentially higher innate ability that also invested more in type 1 human capital. This means that the WR will continue to shift each year until the best worker of the generation born at $T=0$ will reach the top of her productivity age profile, at age 33 in our calibration. This means that the WR record will shift each year between $T=15$ and $T=33$ which corresponds to a window of 18 years of increase. This pattern is depicted in Figure 13. It should also be noted that selection, as measured by the difference between the mean performance (human capital of type 1) among those that select sector 1 and the population mean, will increase over time. This pattern is depicted in Figure 14 for the calibration above.

\subsection{Predictions of the model}

The model makes an important prediction about the timing of the end of the window of increase in the S-shape evolution of the WR. The end of the 
window depends on the age at which performance peaks, say $a^{+}$-in the calibration, $a^{+}=33-$. Let the age at which athletes have established the current WRs in the four disciplines characterized with a S-shape be a proxy for $a^{+}$. Table 1 reports values of $a^{+}$in our 4 disciplines ranging from 27 to 32 years. Using data on the evolution of the GWRR we can estimate the year corresponding to the end of the window and hence the year of the drop in social barrier for each event by simply subtracting to the year of the end of the window our proxy for $a^{+}$. As reported in Table 1, the implied year of the drop of social barrier is 1955 for marathon or 16 years before women were authorized to run the NYC marathon and 29 years before women could run the marathon at the OG. Similarly, for Pole vault, the implied year $T=0$ is 1981 or 11 years before the discipline was ratified by the IAAF and 15 (19) years before the event was organized at the EC (OG respectively) for the first time.

\section{Summary and discussion}

This paper shows that the evolution of the GWRR has not been uniform across disciplines in individual sports. While for most disciplines a linear 
closing of the gender ratio is observed, four disciplines, the 800 meters, pole vault, triple jump and marathon, exhibit a S-shape evolution over time. This paper argues that this pattern is initiated by a sudden drop in the social barrier for women to participate in these four disciplines. This drop in social barrier can be linked to historical events related to women's participation at major events and in particular the $\mathrm{OG}$ or the $\mathrm{WC}$ in these disciplines.

The paper builds a simple economic model of sector self-selection and human capital accumulation with intrinsic disutility (social barriers) to participate in some sectors. It is shown that as social barriers are removed in a sector, the Gender Performance Ratio follows a S-shape over time under very basic assumptions and calibrations. Ability self-selection, measured as the difference between mean ability of women in that sector and population mean, becomes more positive after removal of the social barrier.

This paper is related to the literature on the Gender Pay Gap. As depicted in Figure 15, the US Gender Pay Ratio (GPR) has followed a S-shape over the last 5 decades similar to that of the GWRR in the 800 meters, pole vault, triple jump and marathon. Recently, Mulligan and Rubinstein (2008) have shown that this shape is in fact due to a change in the selection of women into paid employment. The selection of women into paid work has become 
more positive over time. MR08 attributes the change in self-selection to the rise in within gender wage inequality that occurred simultaneously with the S-shape of the GPR. In Mulligan and Rubinstein (2008)'s view, successive changes in the return to labor market skills successively induced women with more of these skills to enter the labor market leading to successive increases in the GPR.

This paper proposes an alternative explanation for the changes in the self-selection into paid work of women and the resulting S-shape of the GPR. In the model outlined in this paper, a drop in the barriers to entry in a sector at $T$ will lead to successive changes in i) the distribution of human capital in that sector (and other sectors too) and ii) self-selection leading to a S-shape in the GPR. The new equilibrium will be reached, i.e. human capital, selfselection and GPR will remain constant, as soon as the generation of women born at $T$ will enter the labor market.

Evidence from athletic disciplines such as 800 meters, pole vault, triple jump and marathon seems to point toward World War II and the women liberation movement of the 60 s as an explanation for the change in selfselection into paid employment observed in the labor market in the 70 s and 80s and the ensuing S-shape in the GPR. The line of thoughts would be that 
following WWII and the women liberation movement of the 60s, labor market participation of women has increased, generation after generation, providing new generations of women with more incentives to invest in labor market skills. Each new generation of women has therefore entered the labor market with more skills than the previous leading to more positive self-selection and a S-shaped GPR. However, since human capital investments of all generations of women born after the liberation movement of women will be similar, the GPR of these generations will also be similar explaining the flattening out of the GPR since the mid 90s.

To make the link between the GPR and the GWRR clearer, it is important to note that the above discussion about self-selection holds for all quantiles. The GPG at all quantiles can be decomposed into a true gender pay gap and a selection effect, i.e. the difference in abilities between women at the $\tau^{\text {th }}$ quantile of the distribution of working women relative to women at the $\tau^{\text {th }}$ quantile of the distribution in the population. Figure 16 clearly shows a S-shape for the median, the 5 th percentile and the 95 th percentile. $^{9}$ The end of the window for the 95 percentile is in the mid-90s and since women-hourly

\footnotetext{
${ }^{9}$ Higher quantiles than the 95 th are tricky to interpret since the CPS march supplements are topcoded with the share of topcoded observations in the vicinity of 2 to $3 \%$ of the selected samples.
} 
wages at the 95 percentile peak at 52 years old, as indicated in Figure 17, the implied year of the drop in social barrier is $1995-52=1943$.

\section{References}

IOC (2009): "FactSheet, Women at the Olympics movement," Report 846.

Leigh, M. H., And T. Bonin (1974): "The Pioneering Role of Madame Alice Milliat and the FSFI in Establishing International Track and Field Competition for Women," Journal of Sport History, 4(1), 72-83.

Mulligan, C. B., and Y. Rubinstein (2008): "Selection, Investment, and Women's Relative Wages Over Time," The Quarterly Journal of Economics, 123(3), 1061-1110.

Munasinghe, L., B. O’Flaherty, and S. Danninger (2001): "Globalization and the Rate of Technological Progress: What Track and Field Records Show," Journal of Political Economy, 109(5), 1132-1149.

Roy, A. (1951): "Some Thoughts on the Distribution of Earnings," Oxford Economic Papers, 3(1), 135-46. 


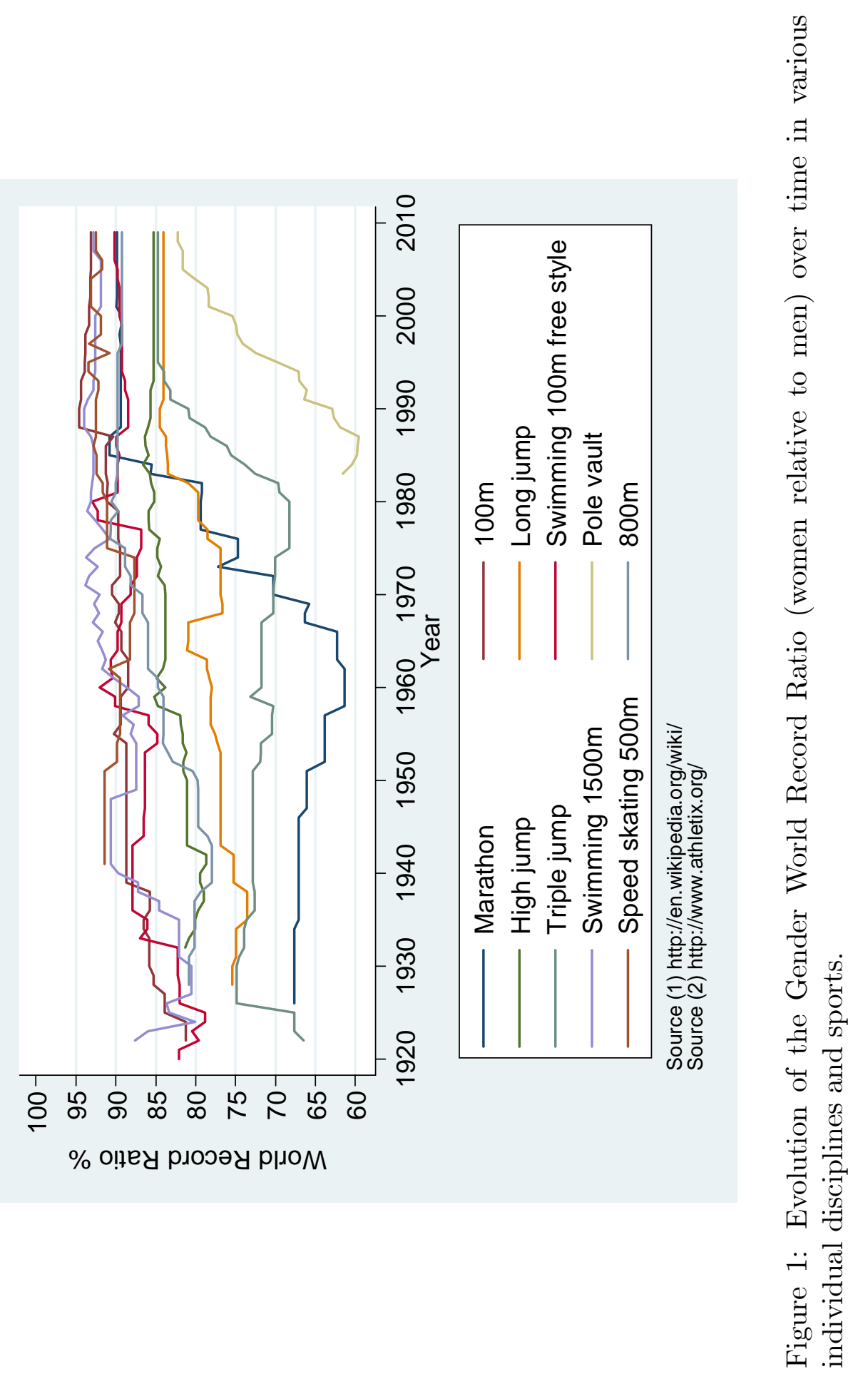




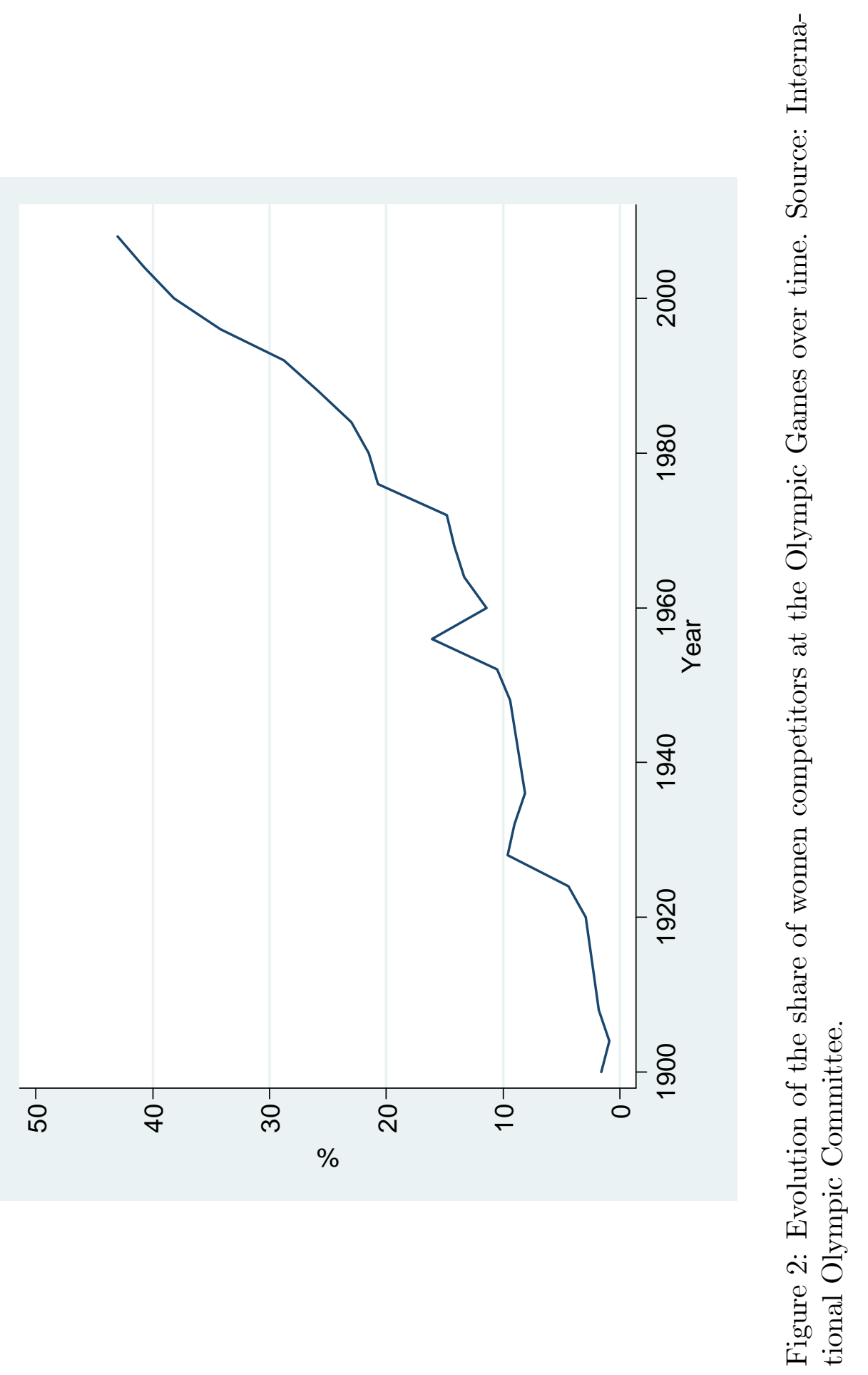




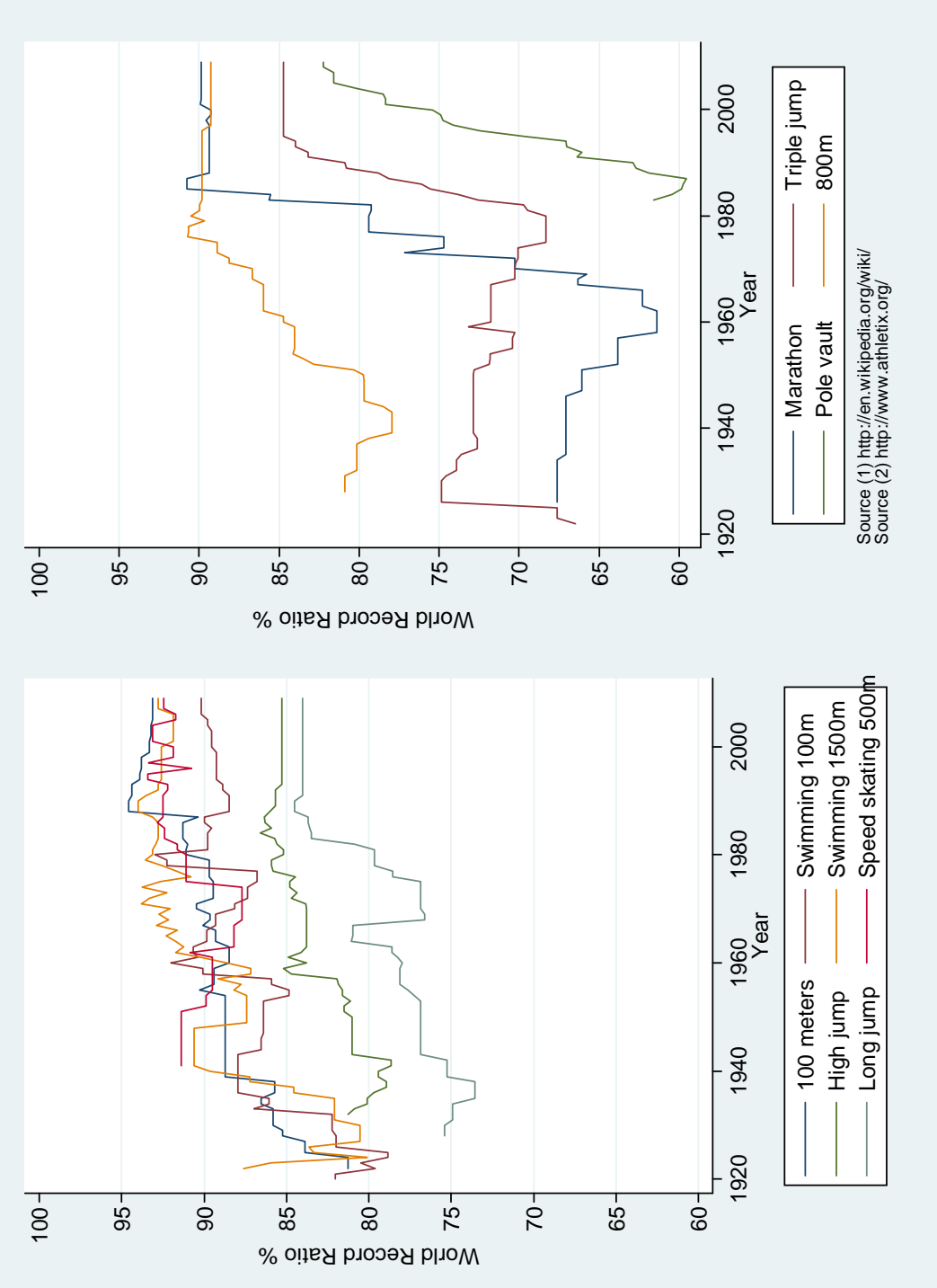

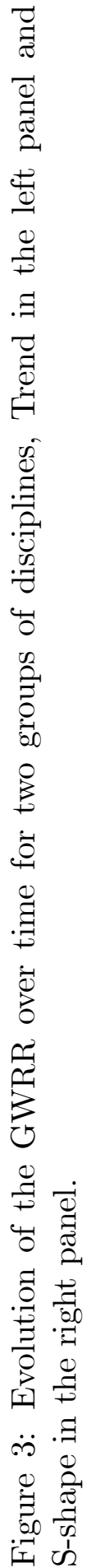




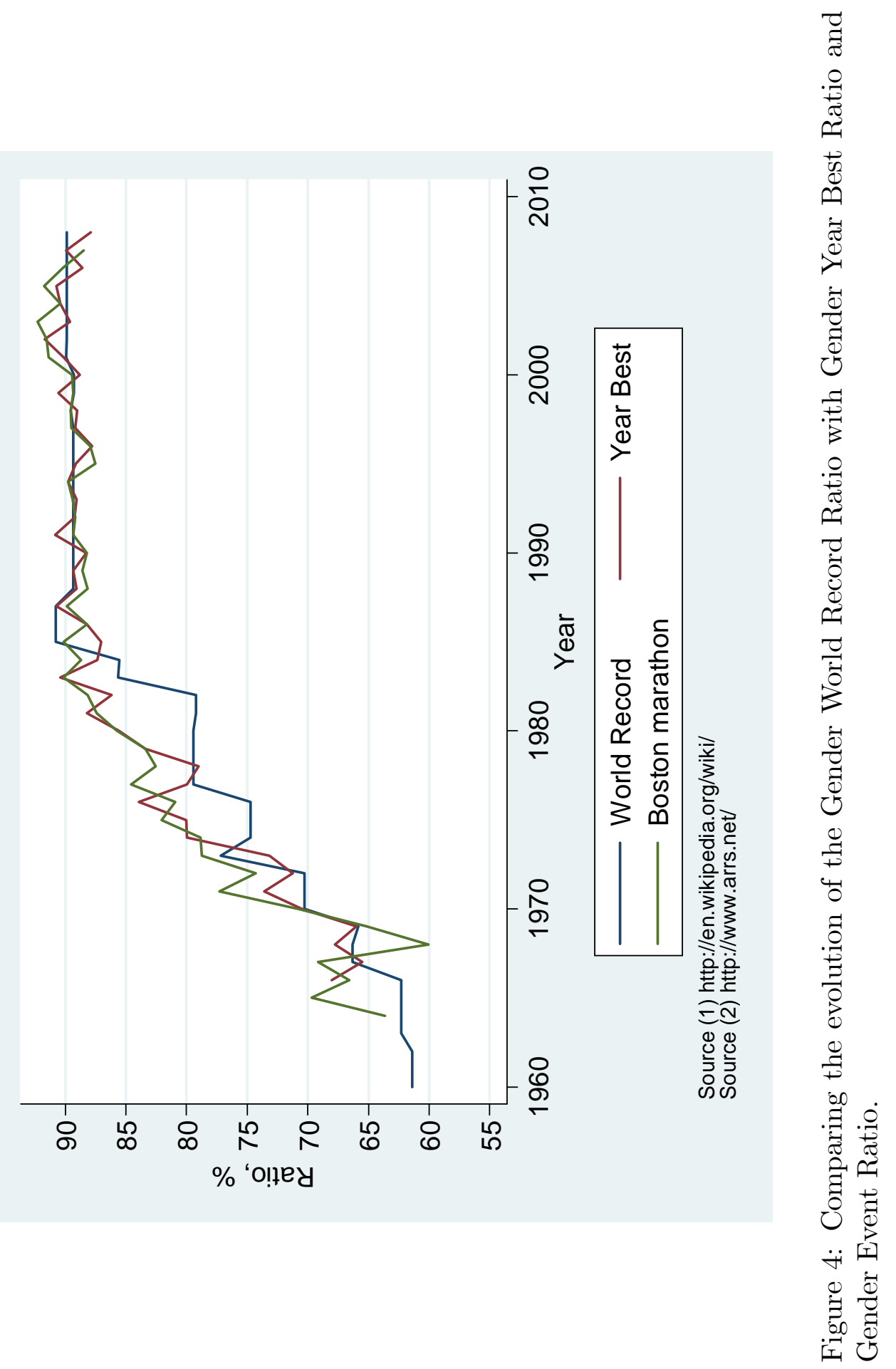




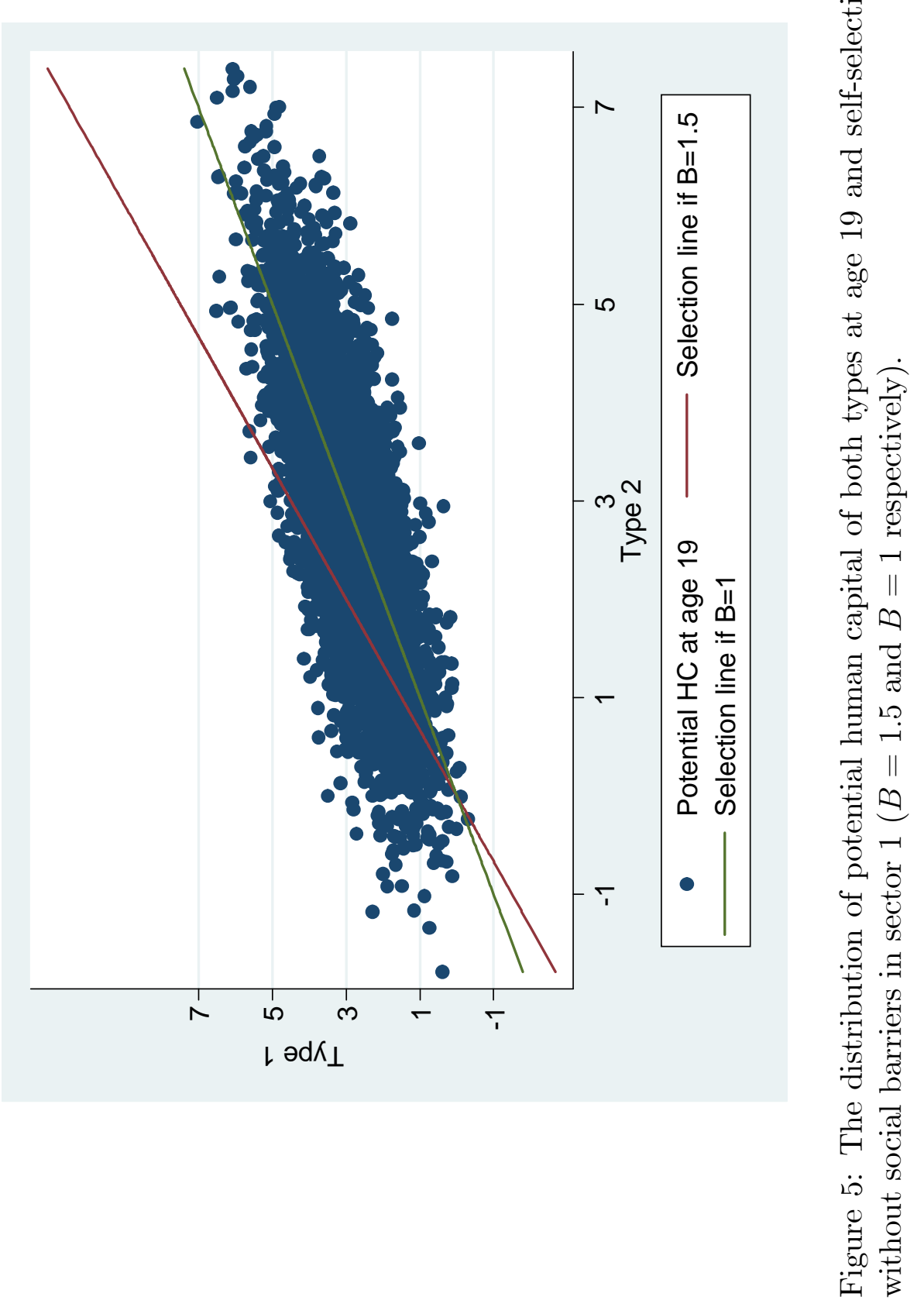




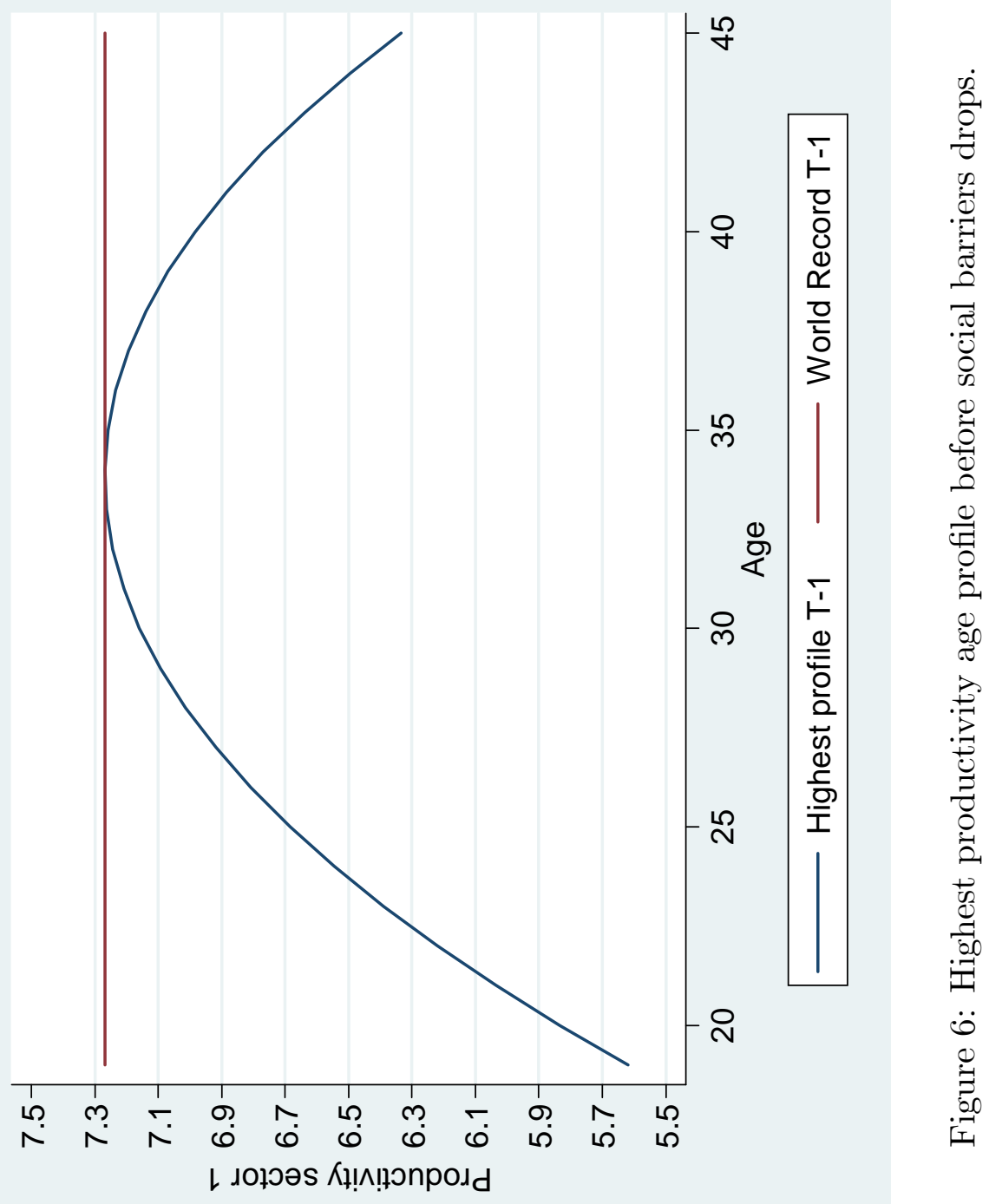




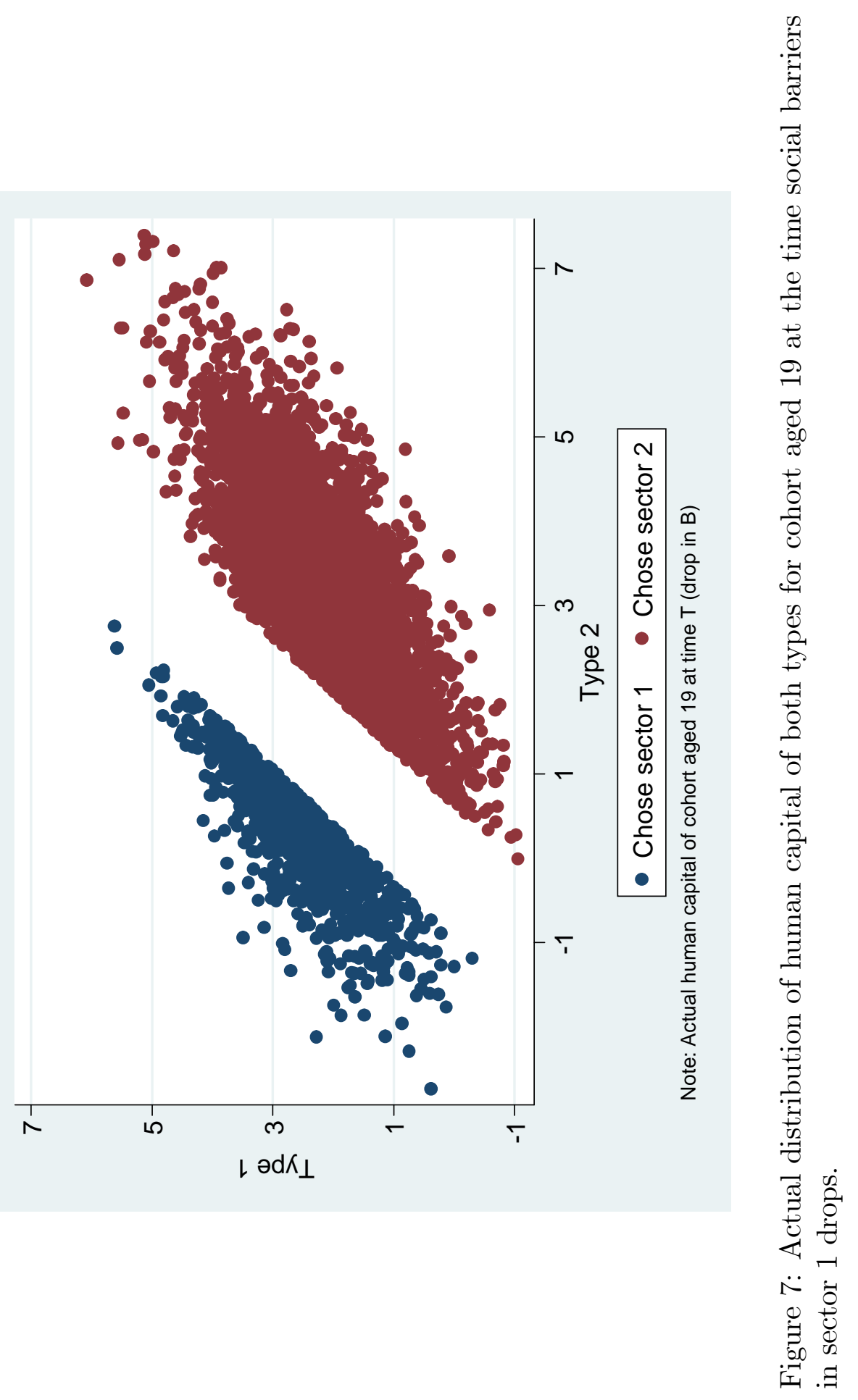




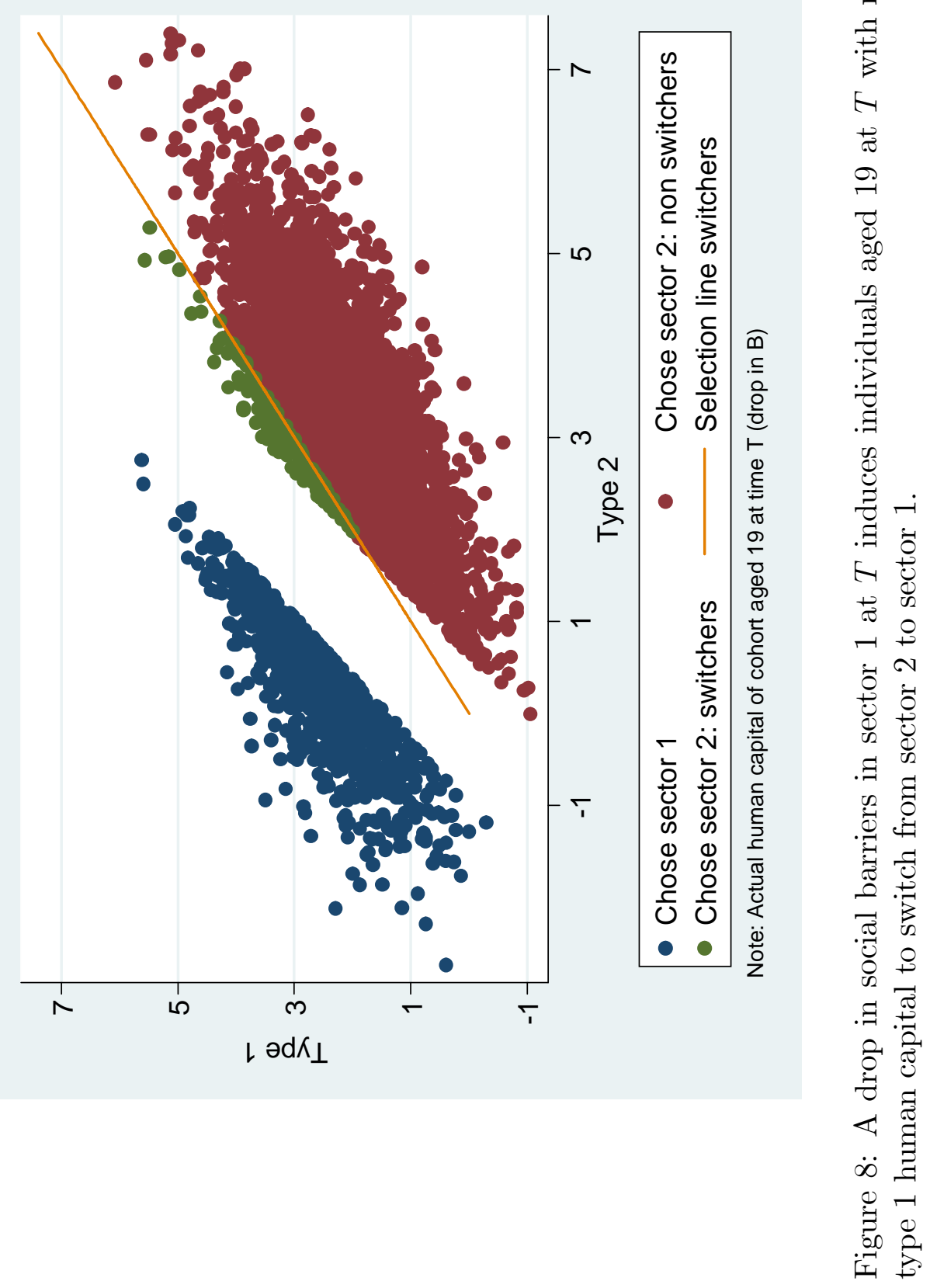




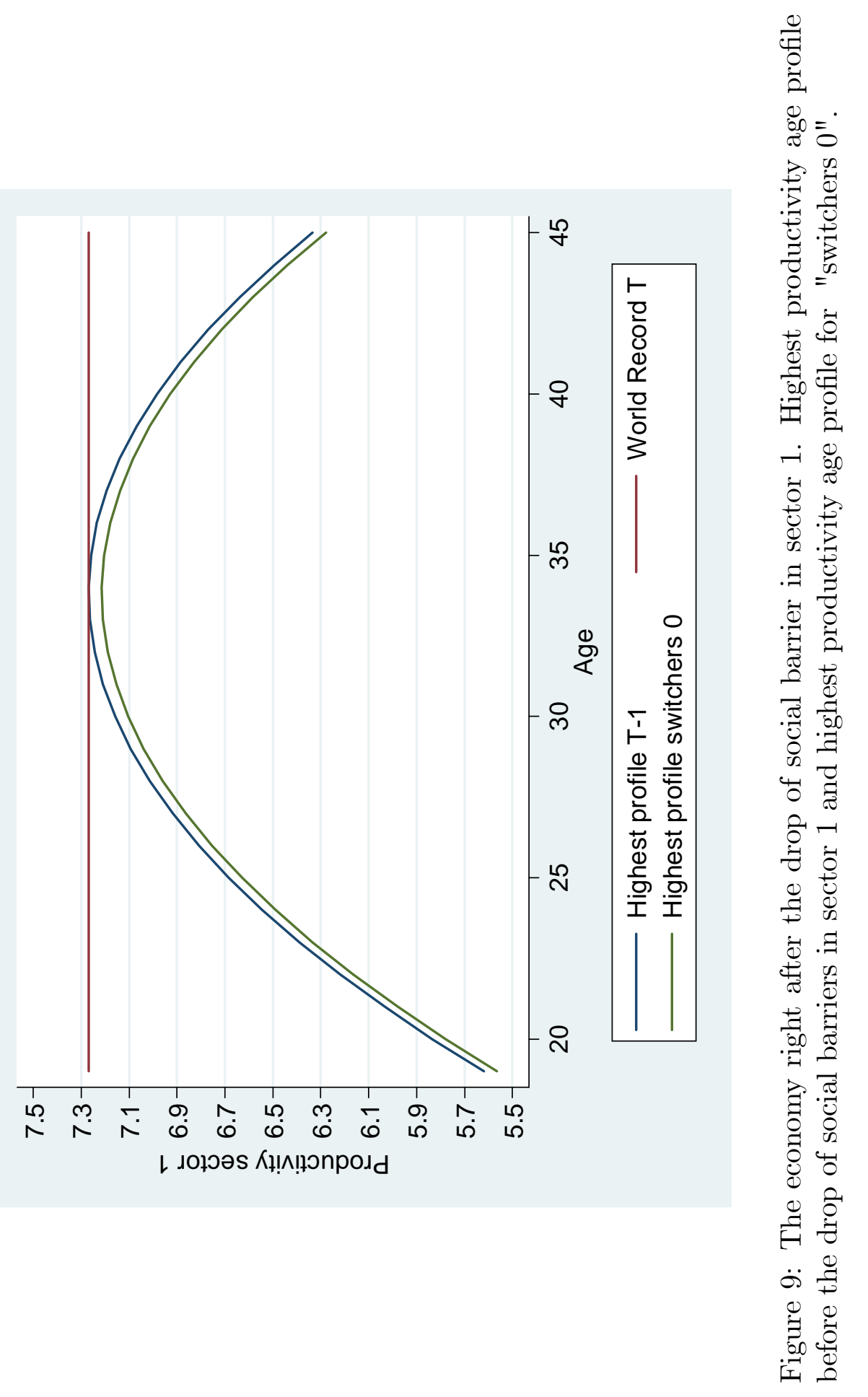




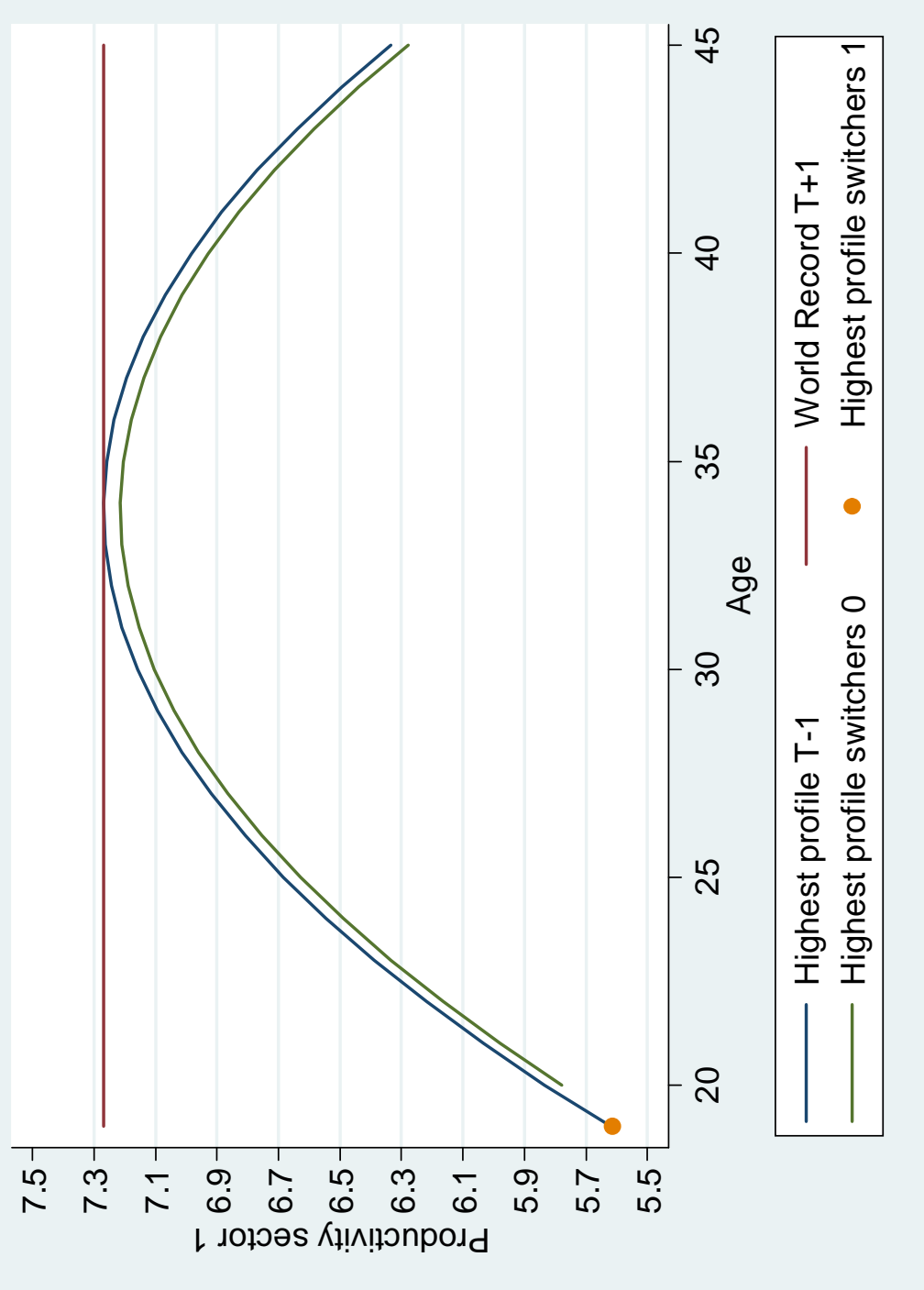

.

D

.

a

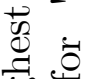

50

可题

-

잉

o

.

岛

ฮี

อ ลี

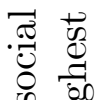

o. .00

.

엄

욤

Ð

売

สี สี

$>$ 응

○్

B $4=$

हैं

응 운

它司

0.

E 0

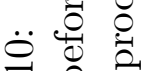

그

일 $\frac{0}{0}$

政 

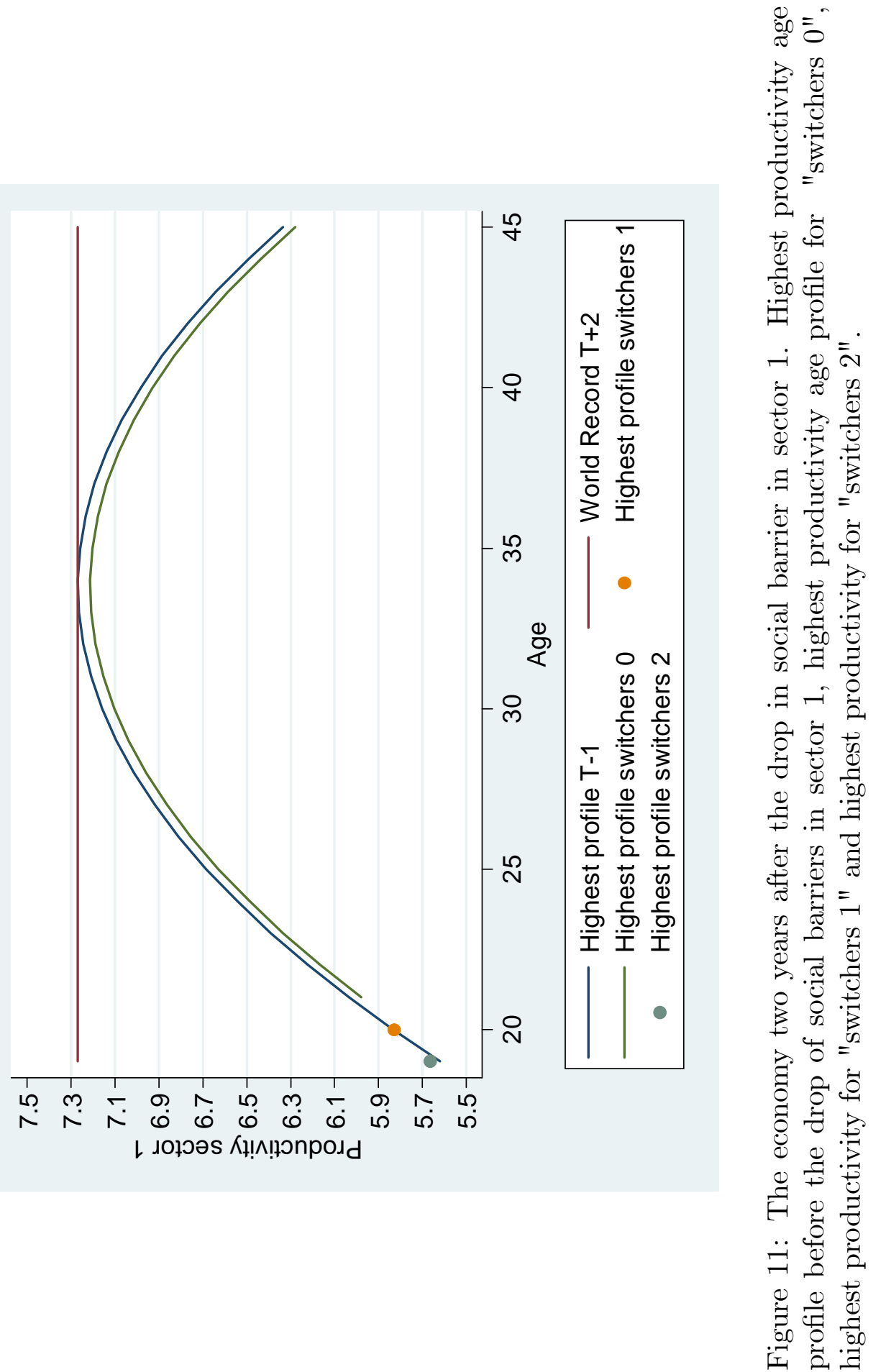


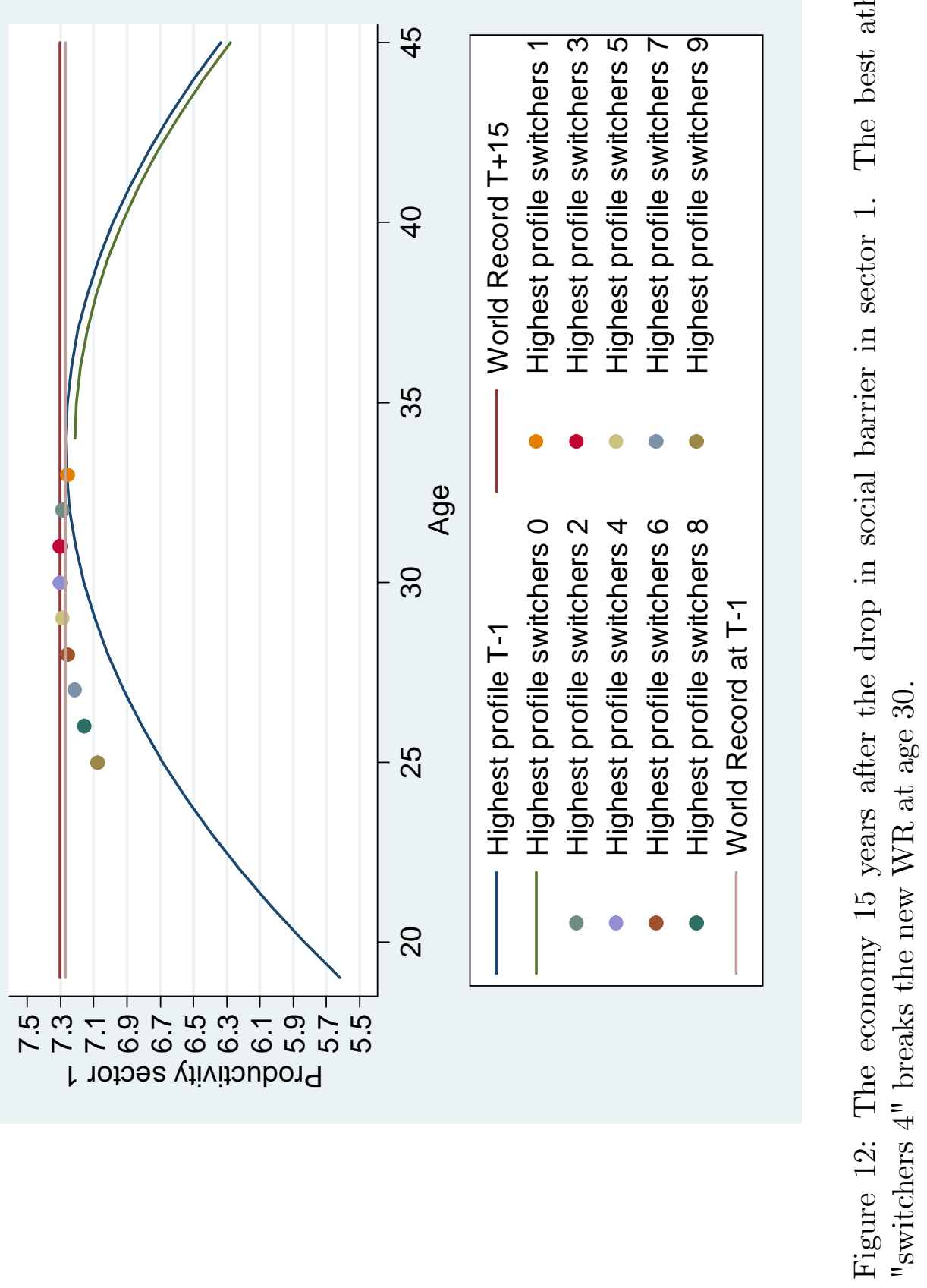




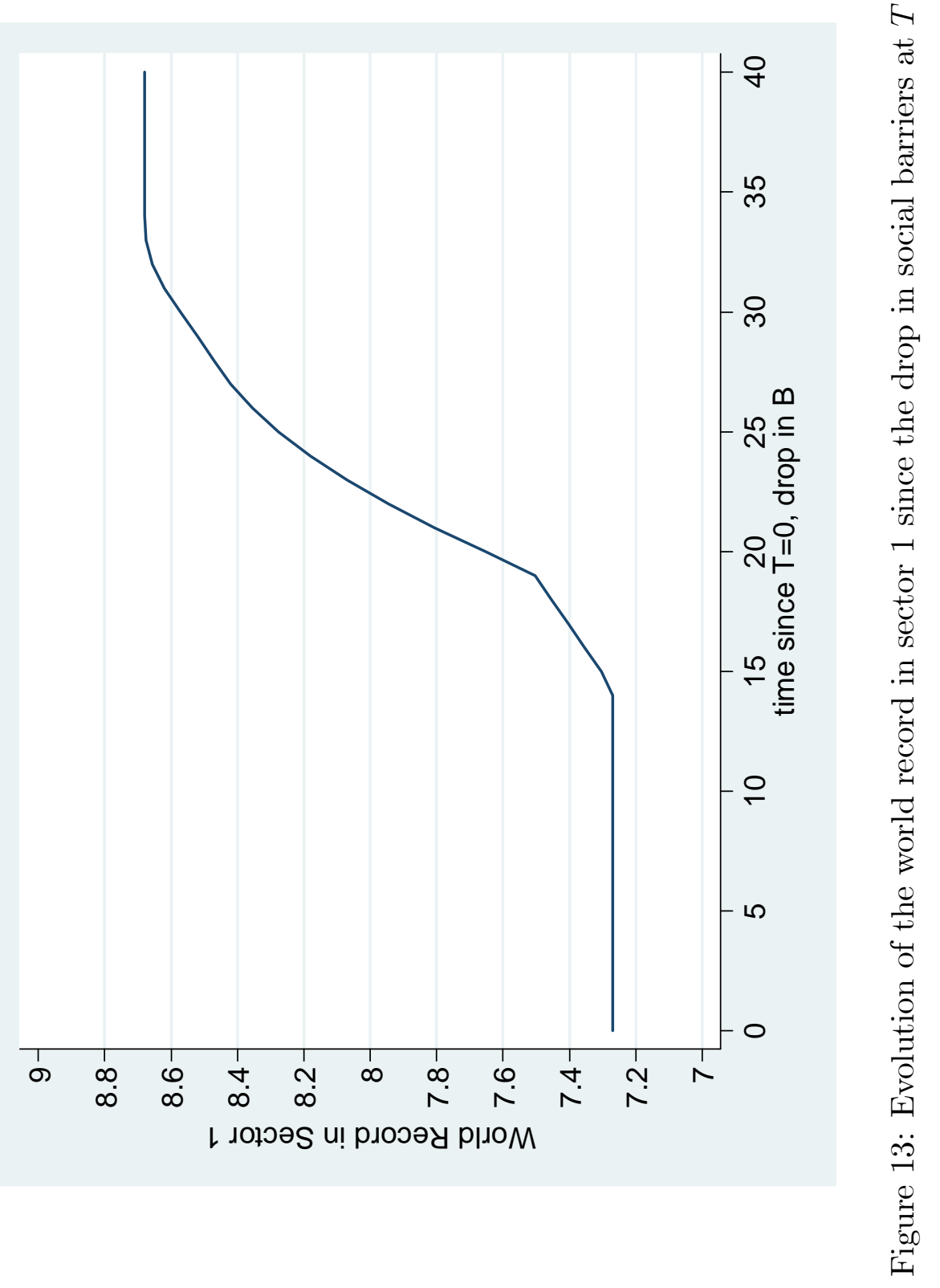



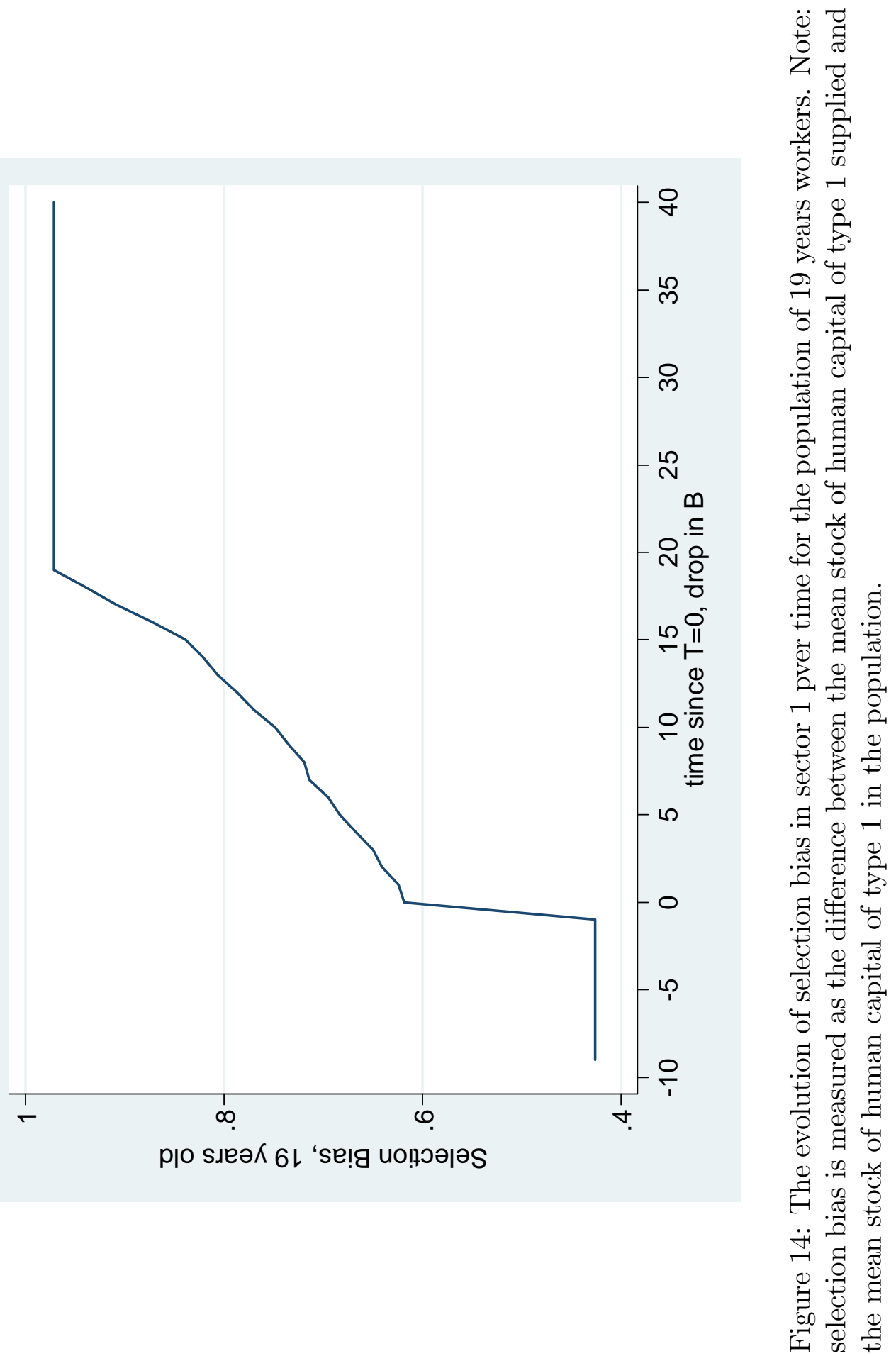


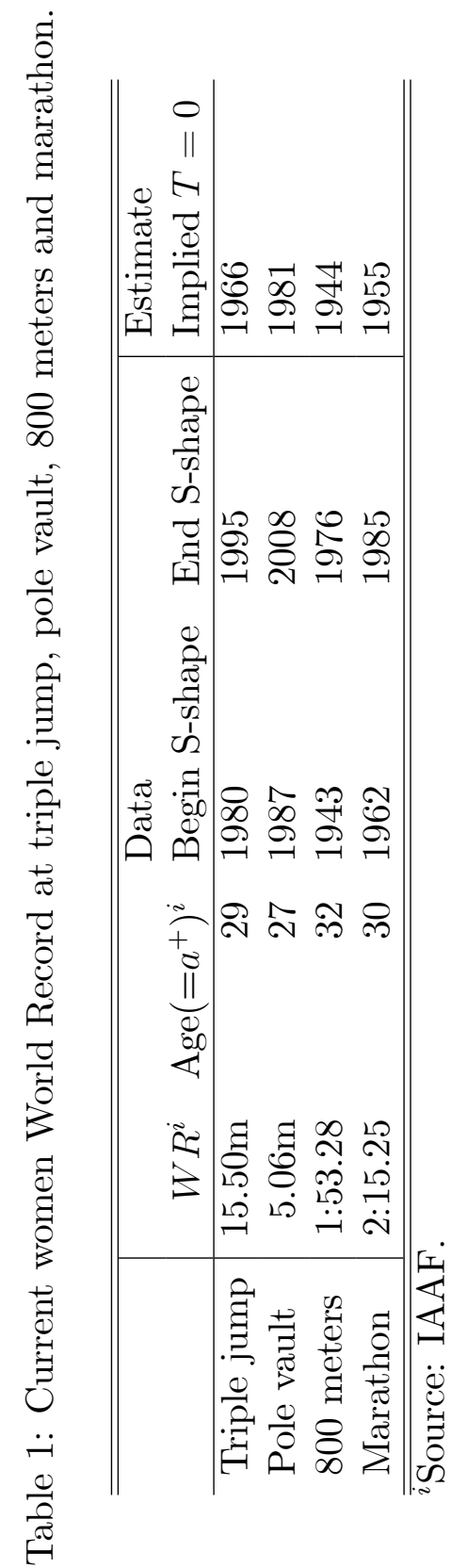



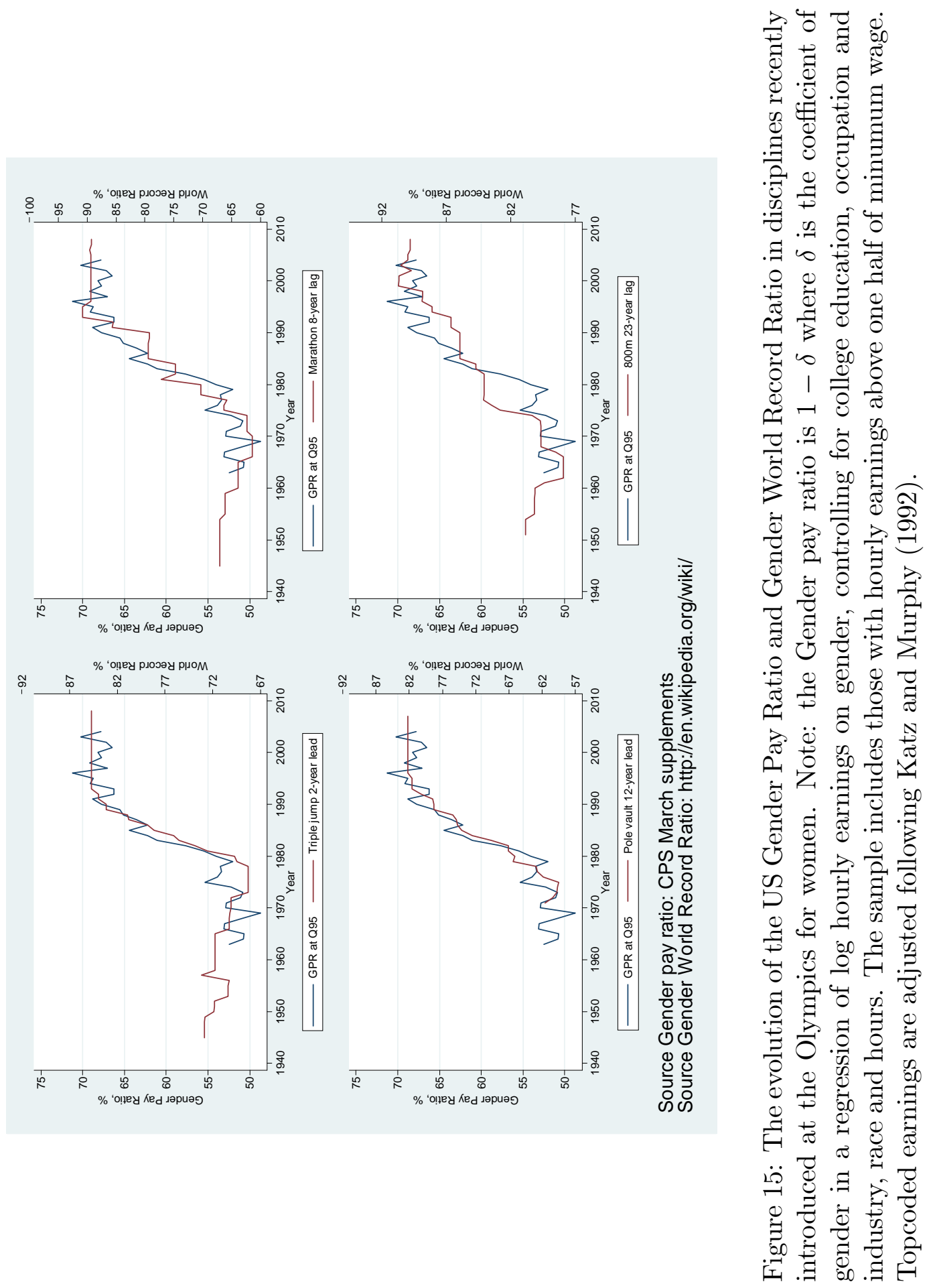

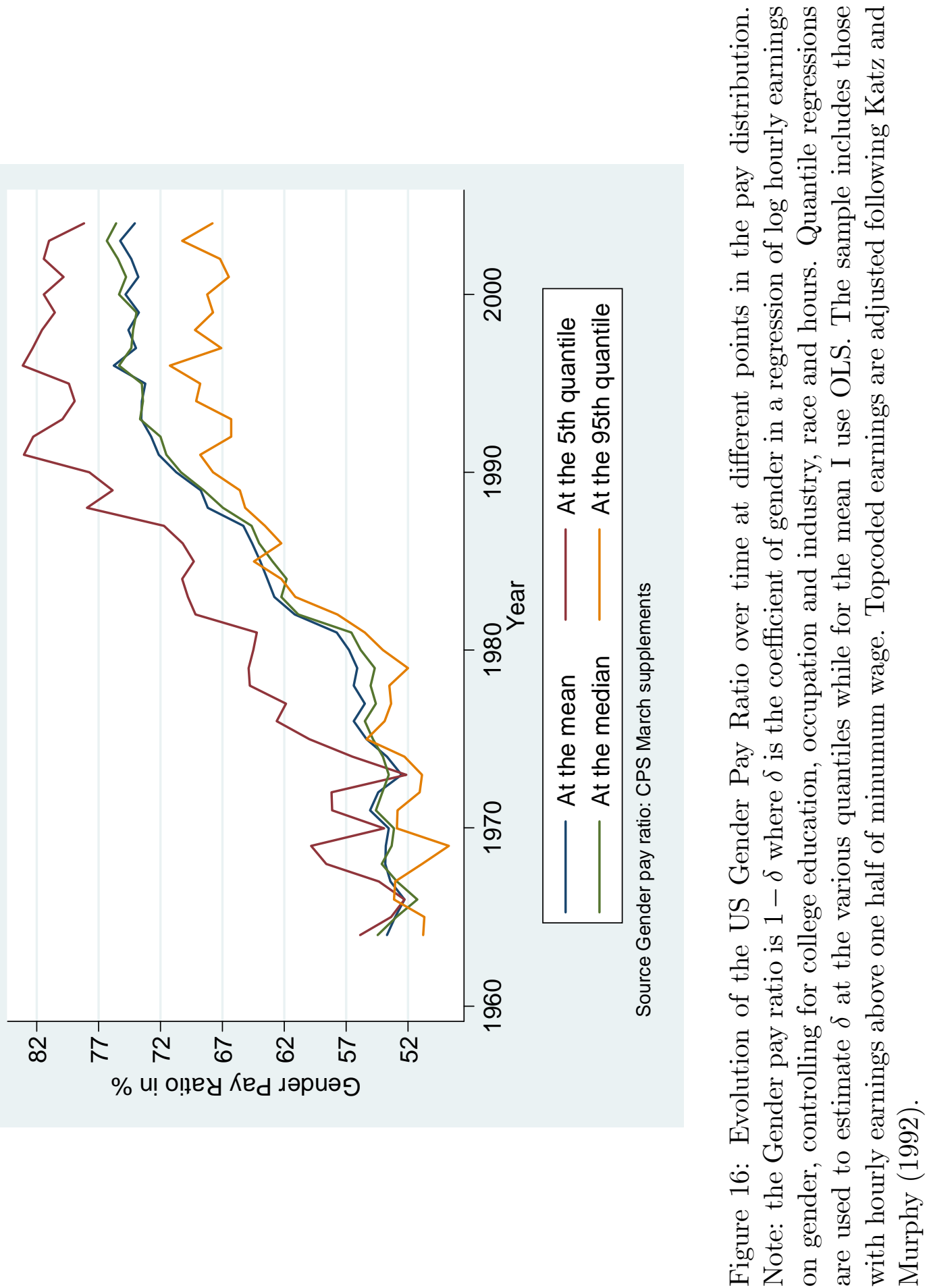


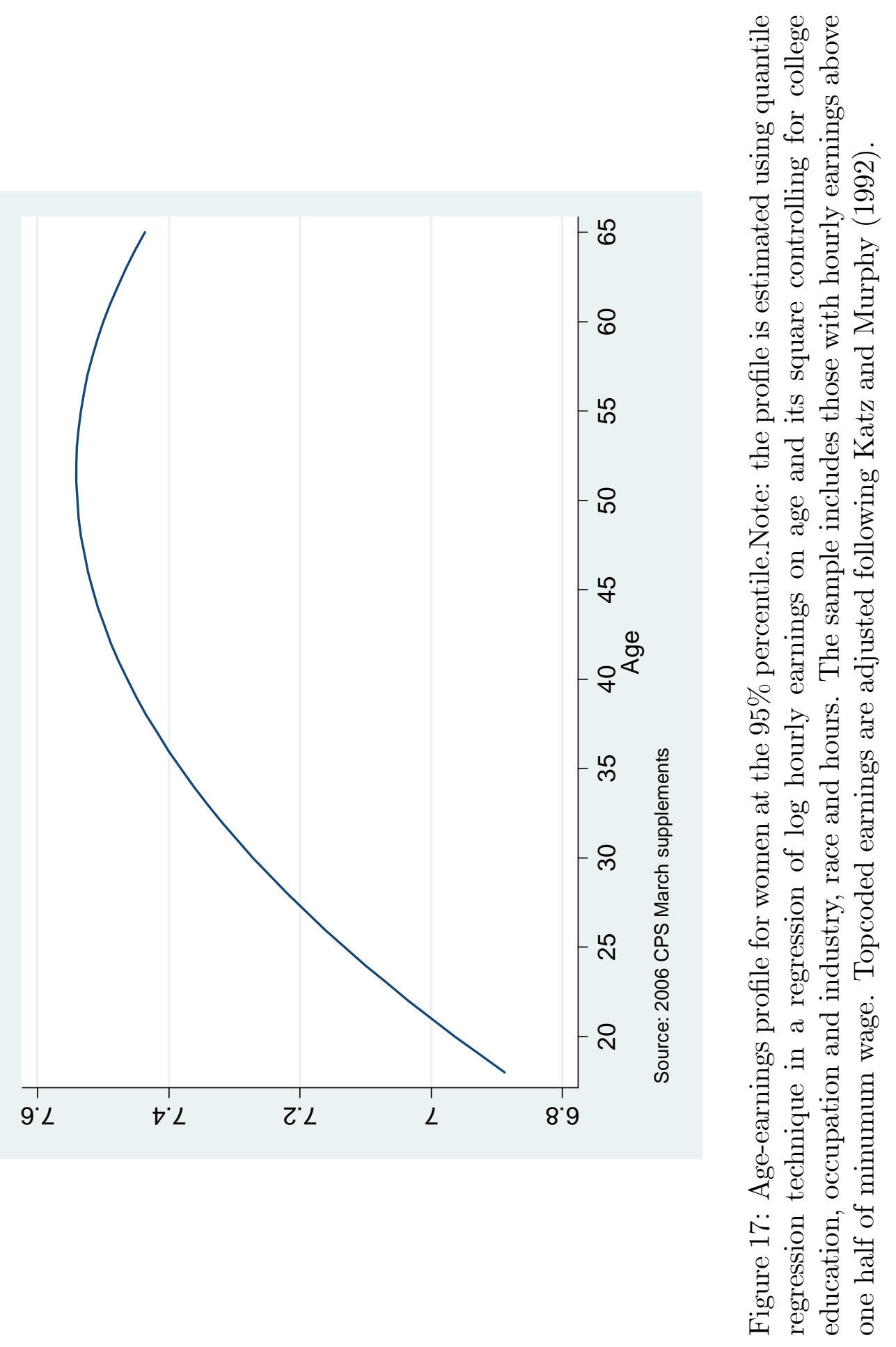

